\title{
COMPETÊNCIAS EMPREENDEDORAS: INVESTIGAÇÃO E MAPEAMENTO DO PERFIL FEMININO
}

Nathalia Berger Werlang ${ }^{1}$

Ana Claudia Korbes ${ }^{2}$

Graciele Tonial $^{3}$

Alessandra Cassol ${ }^{4}$

\footnotetext{
${ }^{1}$ Centro Universitário FAI - UCEFF

${ }^{2}$ Curso de Administração / Centro Universitário FAI - UCEFF / Centro Universitário FAI - UCEFF

${ }^{3}$ Universidade do Oeste de Santa Catarina (UNOESC)

${ }^{4}$ UNC / UnC
} 


\title{
COMPETÊNCIAS EMPREENDEDORAS: INVESTIGAÇÃO E MAPEAMENTO DO PERFIL FEMININO
}

\begin{abstract}
Resumo
O estudo tem como objetivo identificar as competências empreendedoras nas mulheres. A pesquisa é de abordagem quantitativa, o método utilizado é survey, para coleta foi utilizado questionário Likert de 5 pontos, baseado em Lenzi (2008), a amostra é de 97 mulheres. A análise dos dados ocorreu por meio de análise estatística descritiva, os resultados indicam que 96,91\% de mulheres possuem a competência Comprometimento (COM), 90,72\% detém a competência Persistência (PER) e 77,32\% a competência Busca de Informações (BDI), a apontar a preocupação para o desenvolvimento de sua carreira e capacidade competitiva no mercado de trabalho. Do lado oposto, as competências com menor pontuação são a Busca de Oportunidade e Iniciativa (BOI), somando 28,87\%, Estabelecimento de Metas (EDM) e Persuasão e Rede de Contatos (PRC), com 46,39\% cada. Ainda assim, nota-se mulheres a desconstruir paradigmas tradicionais e a buscar a solidificação de sua carreira, bem como desenvolver-se pessoal e profissionalmente.
\end{abstract}

Palavras-chave: Competências Empreendedoras. Empreendedorismo Feminino. Capacidade competitiva. Carreira. 


\section{INTRODUÇÃO}

As crescentes mudanças ocorridas no mundo dos negócios nos últimos anos, apresentam um cenário competitivo e desafiador, e fazem com que a iniciativa empreendedora se torne uma alternativa capaz de incrementar o ambiente de micro e pequenas empresas brasileiras, contribuindo para o desenvolvimento socioeconômico do país.

O empreendedor é visto como ator que dispõe de competências como persistências, assunção ao riso, comprometimento entre outras, sendo desafiado de modo constante a lidar com circunstâncias complexas que transformam e desenvolvem suas qualidades. Segundo Feuerschütte e Godoi (2008), o empreendedor atua de forma a desenvolver as suas competências humanas, habilidades intrínsecas elevadas em situações do cotidiano no mercado de trabalho.

Frente a este novo contexto das organizações, Honma e Teixeira (2011) caracterizam o indivíduo que empreende como o responsável pela gestão de sua empresa, e as competências empreendedoras tornam suas aliadas neste processo. Neste cenário, o papel feminino passa a ser visto com outros olhos no ambiente organizacional, em que o espaço antes dominado pela figura masculina, é dividido com as mulheres em busca de reconhecimento e desenvolvimento no mercado de trabalho (CRAMER et al 2012).

Lomazini, Vicente e Santos (2014) observam que a figura do empreendedor, esta atrelada a criação, manutenção e gestão de suas empresas, e, justificam como de fundamental importância os estudos e análises das competências empreendedoras. Neste contexto, os mesmos autores constatam o crescimento da mulher nos últimos anos em atividades empreendedoras.

De acordo com informações do Global Entrepreneurship Monitor - GEM, (2016) no Brasil, grande parte dos novos empreendimentos foram iniciativa do público feminino, contudo quando analisados os empreendimentos já estabelecidos no mercado, o gênero masculino toma a frente. Os dados também demonstram a maioria feminina dentre os empreendimentos iniciais, com 51,5\%, já para os empreendimentos estabelecidos se tem maior participação do público masculino, igual a 57,3\%. Frente a estes fatores, vê-se a importância em estudar o tema em questão visto a contribuição que a mulher quanto profissional traz para a organização e o destaque de suas competências nas atividades dentro da empresa.

Jonathan (2005) aborda ainda a importância da presença da mulher nas micro e pequenas empresas, aonde esta tem a oportunidade de consolidar carreira e cooperar para a ascensão do panorama socioeconômico no país. Machado, Gazola e Anez (2013, p. 179) observam que "o início de um empreendimento é um processo dinâmico com implicações econômicas, sociais e culturais, e apresenta diferenças quanto a atuação por homens e mulheres." Alguns desafios apontados pelos autores dizem respeito as longas horas da jornada de trabalho, pressões familiares e pouco acesso a financiamento.

Filardi, Barros e Fischmann (2014) relacionam o desenvolvimento do empreendedorismo no Brasil a um momento incomum nos anos 1990, em que, o mercado viuse pressionado pelos planos econômicos, o fechamento de diversas empresas e o aumento do desemprego, que moldou a atividade empreendedora em uma necessidade, justo pela obrigação em empregar pessoas e voltar a movimentar a economia brasileira. Os autores ainda destacam que esse cenário instigou muitas pessoas a realizar tal ato incluindo indivíduos sem

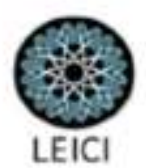


perfil e competências adequadas para a gestão correta das novas empresas, sendo esse, o maior empecilho para o sucesso e sobrevivência dos negócios nos últimos vinte anos.

Isto posto, justifica-se a importância de compreender quais as competências empreendedoras são presentes no público feminino. Sob essa ótica, a presente pesquisa irá contribuir para a construção do conhecimento teórico ao identificar as competências atuais das empreendedoras visto que este hoje é um tema emergente. Do ponto de vista prático, o trabalho irá contribuir com o público feminino ao apontar quais são as competências empreendedoras necessárias para seu desenvolvimento profissional dentro da organização, de modo a contribuir para potencializar a competitividade da empresa.

O trabalho está organizado em cinco seções, a primeira de cunho introdutório; a seção dois que compreende uma abordagem teórica sobre o Empreendedorismo, as Competências Empreendedoras e as produções científicas recentes acerca do tema; na seção três se discorre referente à metodologia empregada na construção do trabalho, em que utilizou-se questionário Likert de 5 pontos, baseado no modelo de Lenzi (2008). Com abordagem quantitativa, a pesquisa se caracteriza como uma pesquisa descritiva com uso se survey, construída no Google Drive e de maneira posterior encaminhada para as respondentes. Quanto a análise de dados, utilizou-se de planilha em excel. Na seção quatro ocorre a descrição e análise dos resultados obtidos; e, na quinta seção apresenta-se as considerações finais em relação aos resultados e as recomendações para futuras pesquisas.

\section{REFERENCIAL TEÓRICO}

Neste tópico serão abordados os principais conceitos teóricos que servirão de base para este estudo. Dá-se início dissertando sobre o Empreendedorismo, as Competências Empreendedoras e por fim abordam-se os estudos recentes sobre o tema empreendedorismo e competências empreendedoras.

\subsection{EMPREENDEDORISMO}

A luz de Carland, Boulton e Carland (1984) o empreendedorismo está relacionado com a procura pertinente por conhecimentos, experiências, inovação e habilidades, que instigam o empreendedor a buscar e compreender o mercado. Enquanto o empreendedor é aquele que tem visão sobre negócios e novas oportunidades para o mercado, tem capacidade de influenciar as pessoas e é apaixonado pela profissão.

Lizote e Verdinelli (2015) corroboram com o conceito de Schumpeter (1989) sobre o empreendedorismo, e observam que o tema é abordado como uma atividade que transforma a economia por meio de inovações, sendo o empreendedor uma pessoa que visa a busca constante por aproveitar as oportunidades e apreender com os erros.

Filion (1999) destaca que uma das competências necessárias para empreender é ser dotado de criatividade, capacidade de definir e atingir metas e estar consciente do ambiente que frequenta para ter a capacidade de identificar oportunidades.

A identificação de uma oportunidade para o desenvolvimento de um negócio antes não explorado, aliado a oportunidades e recursos internos e externos, podem fazer despertar no indivíduo algumas características e competências. Assim, uma oportunidade empreendedora é um espaço em que o indivíduo manifesta sua competência de empreendedor e que passa a

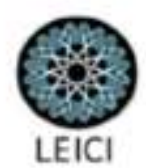


exigir dele o uso de seus saberes, aliados às suas características intrínsecas e aos recursos que o meio proporciona (FEUERSCHÜTTE; GODOI, 2008).

Em seu conceito sobre o empreendedor, Pardini, Brandão e Souki (2008, p. 29), caracterizam como sendo "aquele que corre riscos, vislumbra oportunidades, antecipa-se em relação aos demais na consolidação de ações empreendedoras específicas, utiliza-se de fontes de informações preliminares e da rede de relações sociais na estruturação de suas atividades".

Autores como Cantillon, Adam Smith e Schumpeter são apontados por Zampier e Takahashi (2011) como sendo os pioneiros nos estudos do empreendedorismo. Schumpeter (1997), estabelece em seu conceito que o empreendedor é o indivíduo que tem a capacidade de alterar a economia introduzindo um novo produto ou serviço a ela, na mesma linha, o autor também definiu o perfil do empreendedor que, por sua vez, é a pessoa que possui a vontade de conquistar o sucesso e ser bem-sucedido, que principalmente vê a dificuldade e a transforma em algo possível.

Menezes e Costa (2016) identificaram as três abordagens mais influentes sobre o empreendedorismo, a abordagem behaviorista ou comportamental, a abordagem da literatura gerencial e a abordagem economia. A abordagem behaviorista ou comportamental faz referência às tentativas de definir o perfil e o comportamento dos empreendedores. Possui esse nome devido aos trabalhos de McClelland, um dos behavioristas dos anos 1970 e 1980 . McClelland nomeou a necessidade de realização, "esta seria a motivação que promove a intermediação entre a mudança de um sistema baseado em valores tradicionais para um sistema de valores de caráter empreendedor" (MENEZES; COSTA, 2016, p. 82). Sob a abordagem econômica de Schumpeter, se aplicam as ideias de inovação, risco calculado e desenvolvimento econômico.

$\mathrm{Na}$ abordagem da literatura gerencial os estudos se dirigem às habilidades $\mathrm{e}$ competências empreendedoras referentes ao ambiente organizacional. Essas competências estão pautadas na capacidade de reconhecer oportunidades, relacionar-se em rede, ter aptidão para a gestão, facilidade de leitura e comprometimento com ambições pessoais e da empresa (MELLO et al, 2006).

Indagados sobre o valor do tema em estudo e suas diversas contribuições para as organizações, tem-se a importância em abordar também as Competências Empreendedoras, visto que estas têm função fundamental para o desenvolvimento da competitividade de toda empresa.

\subsection{COMPETÊNCIAS EMPREEDEDORAS}

Autores como Pardini, Brandão e Souki (2008), destacam que as principais competências de um empreendedor são sua capacidade de considerar o ambiente que antecede e sustenta o processo de decisão. Por outro lado, Nassif, Andreassi e Simões (2011, p. 38) trazem que uma competência é "um último nível da característica de um indivíduo, abordando diferentes traços de personalidade, habilidades e conhecimentos, que partem das influências de experiências, treinamentos, educação, família e outras variáveis demográficas".

Para Lenzi et al (2012), as competências são o resultado de uma ligação entre o conhecimento e a estratégia da empresa. Por consequente Lenzi et al (2015), baseados em Orsi e Bose (2003) citam que os primeiros conceitos formados sobre competência surgiram com Boyatzis, Spencer e Spencer e McClelland, em que a definiram como uma soma de

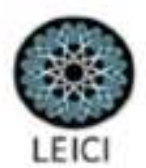


qualidades que um indivíduo possuí para executar qualquer tipo de atividade com um grau de desempenho superior.

Para Lizote e Verdinelli (2015) apontam que estas estão diretamente ligadas com as oportunidades em inovar na prestação de um serviço ou confecção de um novo produto, utilizando os mesmos recursos, obtendo mais qualidade e diminuindo os custos. Silva, Fonseca e Araújo (2015) apontam alguns aspectos que influenciam na formação do comportamento de um empreendedor, como a cultura, necessidades e hábitos. Dessa forma, os empreendedores absorvem determinadas características do lugar em que vivem, assim como ter um modelo de empreendedor na família ou em seu meio, fazem aumentar as chances de um indivíduo desenvolver essas características.

Lizote e Verdinelli (2015) evidenciam que nesta nova economia em que o mercado está inserido, os empreendedores devem adaptar-se com rapidez para garantir o sucesso de seu negócio, trabalhando sempre desenvolver suas competências e volta-las para a satisfação dos clientes. Os mesmos autores embasaram-se em Snell e Lau (1994) para definir um conceito sobre competências empreendedoras, em que, essas são um conjunto de habilidades, conhecimento, atitudes ou visões, que juntas podem agregar valor ao negócio.

Após exploração do ponto conceitual sobre o Empreendedorismo e as Competências Empreendedoras, juntamente com a importância do tema para a manutenção econômica de um país, tem-se a estima em buscar estudos sobre o tema, inserindo o leitor no objetivo principal do trabalho, o público feminino.

\subsection{PESQUISAS SOBRE EMPREENDEDORISMO E COMPETÊNCIAS EMPREENDEDORAS COM MULHERES}

Frente à importância do tema abordado para a manutenção da economia e desenvolvimento de um país, diferentes autores vêm construindo pesquisas referentes ao empreendedorismo e as competências empreendedoras. Assim, foram identificados estudos pertinentes sobre o tema, apresentados a seguir.

Em seu estudo Zampier, Takahashi e Teixeira (2011), objetivaram analisar como as professoras com perfil considerado intraempreendedor, desenvolvem essas competências na docência e pesquisa. Além da função de discente, as participantes da pesquisa participam ativamente nas atividades das IES que atuam, inclusive em cargos antes exclusivamente masculinos, sendo que tem maior preocupação com a realização pessoal ao invés do retorno financeiro, demonstrando grande comprometimento com a IES e o desenvolvimento de sua carreira.

No que se refere à inclusão da mulher no mercado de trabalho, Cramer et al (2012), abordam o novo significado que a presença feminina causa no meio organizacional. Utilizando-se de estudo com abordagem exploratória e aplicação de entrevistas não estruturadas com quatro empresárias, os autores buscaram compreender quais os aspectos sociais que interferem no quesito o que é ser mulher no mundo dos negócios. Neste, concluíram que o modo como essas empresárias gerenciam seu negócio, tem influência de valores e comportamentos adquiridos desde a infância, e que hoje são voltados para a cooperação e os relacionamentos, além de desenvolverem diferentes características durante o tempo, sejam estas o cuidado com as pessoas, a sensibilidade, a intuição, facilidade de relacionamento, facilidade em propor soluções criativas e outros.

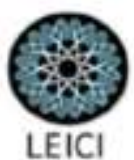


Machado, Gazola e Anez (2013) investigam as razões e dificuldades encontradas por mulheres na criação de empresas, e constaram 3 principais razões que motivam as empreendedoras a iniciar um novo negócio, dentre eles queriam ganhar muito dinheiro, estavam insatisfeitas com o trabalho anterior, e queriam ganhar dinheiro. Quanto as principais dificuldades para criação de empresas as empreendedoras citam, a falta de experiências no ramo, filhos pequenos, a falta de tempo para participar de redes, dificuldade em obter capital e falta de apoio da família,

Instigados pelo aumento da participação da mulher à frente de diversos negócios nos últimos anos, Lomazini, Vicente e Santos (2014) buscam analisar através de um estudo de caso, quais são as competências de uma mulher que geri um empreendimento social. Com os resultados obtidos, os autores diagnosticaram a presença de todas as competências analisadas, tendo destaque para as competências de inovação e competências conceituais, em que a competência social e de comprometimento também se destacam. Por fim sugere-se estudar outros empreendimentos sociais e buscar correlações entre eles, para identificar quais as competências especificas para a gestão de um empreendimento social.

Com base nos resultados das pesquisas relatadas, percebe-se a importância da presença da mulher nas organizações. Estas transpassam características intrínsecas que servem de auxílio para o desempenho de suas funções, bem como apresentam maior interesse na realização pessoal do que financeira. Na seção seguinte aborda-se a metodologia empregada neste estudo.

\section{METODOLOGIA DA PESQUISA}

O presente trabalho é caracterizado com uma abordagem quantitativa. Sousa et al (2007) enfatizam que essa pesquisa segue uma estratégia sistemática e objetiva com a finalidade de originar e aperfeiçoar o conhecimento. Esse tipo de pesquisa permite a quantificação entre variáveis. Sob essa abordagem, analisou-se os dados contraídos sobre as competências empreendedoras das mulheres.

Quanto aos objetivos indicados, o trabalho se caracteriza como uma pesquisa descritiva. Segundo Gil (2002), nesta têm-se como foco básico a construção de relações entre informações, bem como descrever características sobre um público ou fenômeno.

Quanto ao método foi utilizado a pesquisa do tipo survey, que de acordo com Freitas et al (2000), se destaca como método mais utilizado em pesquisas de abordagem quantitativa. em que pode ser definida como a pesquisa que busca obter dados ou informações sobre características, opiniões de ações de algum grupo, normalmente através da aplicação de um questionário.

O instrumento de coleta de dados é caracterizado como questionário, e, foi formulado na plataforma Google Drive, o link para acessar o mesmo foi enviado para as participantes através da rede social Facebook e e-mail, por meio dos contatos pessoais das pesquisadoras. $\mathrm{O}$ questionário é dividido em duas seções, na primeira realiza-se um levantamento quanto ao perfil das respondentes, de modo a abordar a idade, estado civil, se possui filhos, seu nível de escolaridade, se os pais foram ou são donos do próprio negócio, se possui negócio próprio e se considera com alguma característica empreendedora. Na seção dois, aborda-se 30 afirmações breves que compõem um questionário de Likert 5 pontos baseado no instrumento construído por Lenzi (2008).

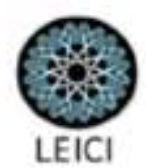


O tratamento dos dados aconteceu em planilha do Microsoft excel, por meio de análise de estatística descritiva sendo possível apresentar indicadores como média, frequência, percentual, valores mínimos e máximos, bem como a distinção e quantificação das competências empreendedoras mais evidentes no público da amostra. Para a análise estatística descritiva, Reis et al (2015) apontam que neste método de análise os dados obtidos se relacionam a apenas uma parte da população em objeto de estudo.

\section{APRESENTAÇÃO E DISCUSSÃO DOS RESULTADOS}

O público alvo da pesquisa caracteriza-se por mulheres de todo o Brasil, maiores de dezoito anos e ativas no mercado de trabalho, a resultar em um total de 104 respondentes, sete das participantes autodeclararam não estar trabalhando, portanto foram excluídas da amostra, o que resultou em uma amostra de 97 questionários.

\subsection{PERFIL DA AMOSTRA}

Dentre as mulheres respondentes, a faixa etária agrupou-se dos 19 aos 36 anos, representando $76,04 \%$ do total. Quanto ao estado civil, 63,92\% das participantes estão solteiras e $22,68 \%$ autodeclaram-se casadas, $13,40 \%$ declaram-se divorciadas, viúva ou em união livre. Apenas $24,74 \%$ das mulheres possuem filhos e a renda mensal com maior representatividade concentra-se entre $\mathrm{R} \$ 938,00$ e $\mathrm{R} \$ 3748,00$, igual a 56,70\% da amostra. A Tabela 01 apresenta o nível de escolaridade do público da amostra.

Tabela 01: Escolaridade

\begin{tabular}{|c|c|c|}
\hline Nível de Escolaridade & Quant. Respondentes & $\%$ \\
\hline $1^{\circ} \mathrm{Grau}$ & 2 & 2,06 \\
\hline $2^{\circ} \mathrm{Grau}$ & 17 & 17,53 \\
\hline $3^{\circ} \mathrm{Grau} /$ Graduação & 54 & 55,67 \\
\hline Especialização & 16 & 16,49 \\
\hline Mestrado/ Doutorado & 8 & 8,25 \\
\hline TOTAL & 97 & 100,00 \\
\hline
\end{tabular}

Fonte: Dados da pesquisa

Destaca-se que 55,67\% das mulheres com qualificação de nível superior, seguida de qualificação de $2^{\circ}$ Grau e Especialização, condizentes com 34,02\%. Contudo, apesar da pouca participação de respondentes com qualificação de $1^{\circ}$ Grau, fatores como a cultura, necessidade e hábitos podem influenciar e contribuir para o comportamento empreendedor (SILVA, FONSECA; ARAÚJO, 2015).

Ainda, 55,67\% das mulheres declaram que seus pais não têm negócio próprio e $44,33 \%$ afirmam que seus pais possuem algum empreendimento, em que se percebe que apenas cerca da metade das empreendedoras que já tem contato com um negócio de família desde jovens constituem no futuro um negócio próprio. Além disso, destas que são filhas de empreendedores, 86,05\% afirmam já terem trabalhado nos negócios da família.

Referente ao setor de atuação, 53,61\% das participantes atua em empresa privada, $20,62 \%$ em empresa pública e apenas $25,77 \%$ em um negócio próprio. Os ramos de atuação em destaque são o comércio, a educação e o agronegócio, juntos representam 32,99\% do total. A Tabela 02 traz as cidades com maior participação na pesquisa. 
Tabela 02: Cidade/ Estado das participantes.

\begin{tabular}{|c|c|c|}
\hline Estado & Quant. Respondentes & $\%$ \\
\hline Santa Catarina & 82 & 84,54 \\
\hline Rio Grande do Sul & 13 & 13,40 \\
\hline Mato Grosso & 1 & 1,03 \\
\hline Paraná & 1 & 1,03 \\
\hline TOTAL & 97 & 100,00 \\
\hline
\end{tabular}

Fonte: Dados da pesquisa

É possível observar a intensa participação das mulheres da região Sul, principalmente que residem em municípios de Oeste de Santa Catarina, a representar 84,54\% do total. Finalmente, para mapear o perfil das participantes, estas foram questionadas sobre seu perfil empreendedor, e 86,60\% afirmam possuir alguma característica empreendedora. Dentre elas, foram citadas a inovação, liderança, proatividade e a visão.

A próxima subseção analisa as 30 competências empreendedoras de Lenzi (2008), mapeadas no público da amostra.

\subsection{COMPETÊNCIAS EMPREENDEDORAS}

A Tabela 03 demonstra a média, desvio padrão, mínimo e máximo de todas as afirmações relacionadas as dez competências citadas por Lenzi (2008).

Tabela 03 - Diagnostico das Competências Empreendedoras

\begin{tabular}{|c|c|c|c|c|}
\hline Afirmações & Média & $\begin{array}{l}\text { Desvio } \\
\text { Padrão }\end{array}$ & Mínimo & Máximo \\
\hline \multicolumn{5}{|c|}{ BUSCA DE OPORTUNIDADE E INICIATIVA } \\
\hline $\begin{array}{l}\text { Lidera ou executa novos projetos, ideias e estratégias que } \\
\text { visam conceber, reinventar, produzir ou comercializar } \\
\text { novos produtos ou serviços. }\end{array}$ & 3,30 & 1,02 & 1 & 5 \\
\hline $\begin{array}{l}\text { Toma iniciativas pioneiras de inovação gerando novos } \\
\text { métodos de trabalho, negócios, produtos ou mercados para } \\
\text { a empresa. }\end{array}$ & 3,26 & 0,99 & 1 & 5 \\
\hline $\begin{array}{l}\text { Produz resultado para a empresa decorrente da } \\
\text { comercialização de produtos ou serviços gerados da } \\
\text { oportunidade de negócio que identificou e captou no } \\
\text { mercado }\end{array}$ & 3,34 & 1,05 & 1 & 5 \\
\hline \multicolumn{5}{|c|}{ CORRER RISCOS CALCULADOS } \\
\hline $\begin{array}{l}\text { Avalia o risco de suas ações na empresa ou no mercado por } \\
\text { meio de informações coletadas. }\end{array}$ & 4,04 & 0,87 & 1 & 5 \\
\hline Age para reduzir os riscos das ações propostas. & 4,02 & 0,93 & 1 & 5 \\
\hline $\begin{array}{l}\text { Está disposto a correr riscos, pois eles representam em } \\
\text { desafio pessoal e poderão de fato trazer bom retorno para a } \\
\text { empresa. }\end{array}$ & 3,86 & 0,81 & 2 & 5 \\
\hline \multicolumn{5}{|c|}{ EXIGÊNCIA DE QUALIDADE E EFICIÊNCIA } \\
\hline $\begin{array}{l}\text { Suas ações são muito inovadoras, trazendo qualidade e } \\
\text { eficácia nos processos. }\end{array}$ & 3,42 & 0,87 & 2 & 5 \\
\hline $\begin{array}{l}\text { É reconhecido por satisfazer seus clientes internos e } \\
\text { externos por meio de suas ações e resultados. }\end{array}$ & 3,96 & 0,89 & 1 & 5 \\
\hline
\end{tabular}




\begin{tabular}{|c|c|c|c|c|}
\hline $\begin{array}{l}\text { Estabelece prazos e os cumpre com padrão de qualidade } \\
\text { reconhecido por todos. }\end{array}$ & 4,16 & 0,86 & 1 & 5 \\
\hline \multicolumn{5}{|l|}{$\begin{array}{ll}\text { PERSISTÊNCIA } \\
\end{array}$} \\
\hline $\begin{array}{l}\text { Age para driblar ou transpor obstáculos quando eles se } \\
\text { apresentam. }\end{array}$ & 4,26 & 0,79 & 2 & 5 \\
\hline $\begin{array}{l}\text { Não desiste em situações desfavoráveis e encontra formas } \\
\text { de atingir os objetivos. }\end{array}$ & 4,27 & 0,74 & 1 & 5 \\
\hline $\begin{array}{l}\text { Admite ser responsável por seus atos e resultados, } \\
\text { assumindo a frente para alcançar o que é proposto. }\end{array}$ & 4,55 & 0,62 & 3 & 5 \\
\hline \multicolumn{5}{|l|}{$\begin{array}{l}\text { COMPROMETIMENTO } \\
\end{array}$} \\
\hline $\begin{array}{l}\text { Conclui uma tarefa dentro das condições estabelecidas, } \\
\text { honrando os patrocinadores e parceiros internos. }\end{array}$ & 4,41 & 0,66 & 3 & 5 \\
\hline $\begin{array}{l}\text { Quando necessário, "coloca a mão na massa" para ajudar a } \\
\text { equipe a concluir um trabalho. }\end{array}$ & 4,77 & 0,47 & 3 & 5 \\
\hline $\begin{array}{l}\text { Está disposto a manter os clientes (internos e externos) } \\
\text { satisfeitos e de fato consegue. }\end{array}$ & 4,29 & 0,69 & 3 & 5 \\
\hline \multicolumn{5}{|c|}{ BUSCA DE INFORMAÇÕ̃ES } \\
\hline $\begin{array}{l}\text { Vai pessoalmente atrás de informações confiáveis para } \\
\text { realizar um projeto. }\end{array}$ & 4,39 & 0,74 & 2 & 5 \\
\hline $\begin{array}{l}\text { Investiga pessoalmente novos processos para seus projetos } \\
\text { ou ideias inovadoras. }\end{array}$ & 3,98 & 0,88 & 2 & 5 \\
\hline $\begin{array}{l}\text { Quando necessário, consulta pessoalmente especialistas } \\
\text { para lhe ajudar em suas ações. }\end{array}$ & 4,16 & 0,90 & 1 & 5 \\
\hline \multicolumn{5}{|c|}{ ESTABELECIMENTO DE METAS } \\
\hline $\begin{array}{l}\text { Define suas próprias metas, independente do que é imposto } \\
\text { pela empresa. }\end{array}$ & 3,68 & 1,03 & 1 & 5 \\
\hline $\begin{array}{l}\text { Suas metas são claras e especificas, e entendidas por todos } \\
\text { os envolvidos. }\end{array}$ & 3,94 & 0,69 & 3 & 5 \\
\hline $\begin{array}{l}\text { Suas metas são mensuráveis e perfeitamente acompanhadas } \\
\text { por todos da equipe. }\end{array}$ & 3,74 & 0,82 & 1 & 5 \\
\hline
\end{tabular}

\section{PLANEJAMENTO E MONITORAMENTO SISTEMÁTICOS}

Elabora planos com tarefas e prazos bem definidos e claros. Revisa constantemente seus planejamentos, adequando-os quando necessário.

É ousado na tomada de decisões, mas se baseia em informações e registros para projetar resultados.

\begin{tabular}{|l|l|l|l}
3,99 & 0,86 & 1 & 5 \\
\hline 4,00 & 0,84 & 2 & 5 \\
\hline 3,79 & 0,83 & 2 & 5 \\
\hline
\end{tabular}

\section{PERSUAÇÃO E REDE DE CONTATOS}

Consegue influenciar outras pessoas para que sejam parceiros em seus projetos viabilizando recursos necessários para alcançar os resultados propostos. Consegue utilizar pessoas-chave para atingir os resultados que se propõe ou para conseguir os recursos necessários. Desenvolve e fortalece sua rede de relacionamento interna e externa à empresa.

\section{INDEPENDÊNCIA E AUTO CONFIANÇA}

Está disposto a quebrar regras, suplantar barreiras e superar obstáculos já enraizados na empresa.

Confia em seu ponto de vista e o mantém mesmo diante de oposições.

É confiante nos seus atos e enfrenta desafios sem medo.

\begin{tabular}{|c|c|c|c}
\hline 3,73 & 0,80 & 2 & 5 \\
\hline 3,59 & 0,87 & 1 & 5 \\
\hline
\end{tabular}

Fonte: Dados da pesquisa

\begin{tabular}{|c|c|c|c}
\hline 3,54 & 1,06 & 1 & 5 \\
\hline 3,81 & 0,85 & 2 & 5 \\
\hline 3,88 & 0,78 & 2 & 5 \\
\hline
\end{tabular}




As questões citadas fazem referência a percepção das mulheres sobre as dez competências empreendedoras abordadas, a análise da média traduz um destaque para o comportamento voltado ao comprometimento e a persistência, bem como a busca por informações, competências que compõem o perfil empreendedor. Se sobressaem as competências que somaram média igual ou superior a 4 .

Destaca-se o interesse com a realização das tarefas e êxito nos objetivos com média 4,77 , em que a colaboradora "coloca a mão na massa" pela equipe (COM), é responsável por suas atitudes e consequências, em que a média 4,55 demonstra a vontade em assumir a frente para conseguir alcançar os objetivos (PER). Alcançou-se média 4,41 no que se refere a cumprir prazos e metas, bem como atender as expectativas de parceiros (COM).

Jonathan (2005) reconhece a forte presença de características como o comprometimento e a persistência dentre as mulheres de seu estudo, prevalece o destaque para as muitas dificuldades durante sua carreira e satisfação na conquista de seus objetivos e crescimento do empreendimento.

O interesse pela busca de informações confiáveis se apresenta com média 4,39, assim como demonstra disposição por manter todos os clientes satisfeitos com média de 4,29 (COM). A persistência mante-se em média 4,26 e 4,27, destaca-se o âmbito em superar cenários desfavoráveis e encontrar alternativas para superar dificuldades e alcançar os objetivos. A excelência em cumprir prazos e tarefas com qualidade apresenta média 4,16 (EQE).

A mesma média se apresenta quanto a responsabilidade e comprometimento em realizar suas atividades com sucesso, de modo a procurar por informações quando necessário com especialistas e/ ou colegas de trabalho (BDI). A competência CRC mantem-se em média de 4,04 e 4,02, dá-se ênfase para o cuidado em tomar decisões e ações dentro da organização, por arremate, a competência Planejamento e Monitoramento Sistemático, que diz respeito a revisão e adequação de planejamentos e metas, soma média 4.

Em seu estudo Cramer et al (2012) identificou que o modo como as empreendedoras realizam a gestão de seu negócio é influenciado por aspectos culturais adquiridos principalmente na infância. Destaca ainda a acentuada cobrança que as mesmas têm por parte da família e sociedade para a gestão de seu negócio, de modo a ressaltar a importância de características como Persistência e Comprometimento para seu perfil empreendedor.

Lenzi (2008) observa a soma mínima de 12 pontos por competência para o indivíduo ser considerado dotado da característica empreendedora. Para a construção e analise do Gráfico 01 e da Tabela 04, foram consideradas apenas as respostas de mulheres que atingiram as competências. O primeiro apresenta uma visão geral da participação de cada competência entre as respondentes, no qual observa-se com veemência a manifestação do Comprometimento e Persistência entre as mulheres da amostra, bem como a Busca de informações e o Planejamento. 
Gráfico 01: Análise das Competências Empreendedoras

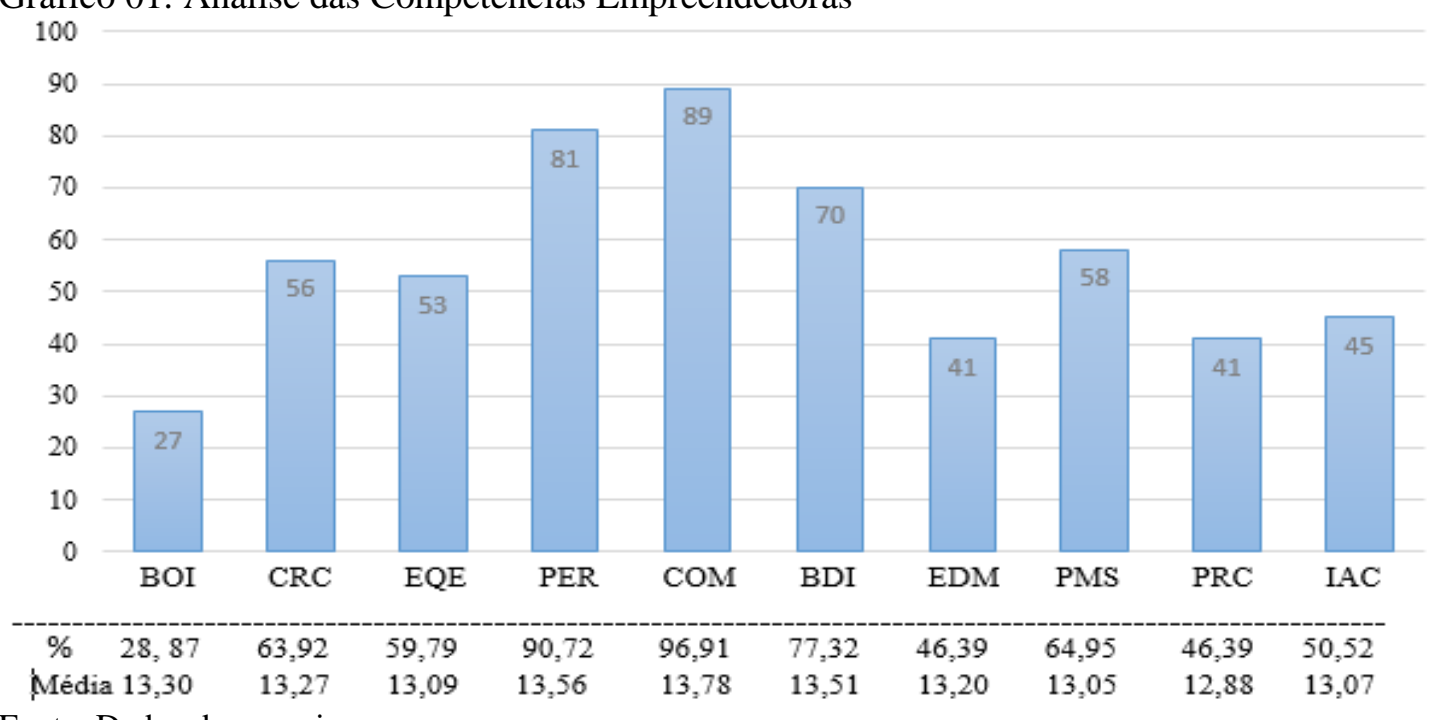

Fonte: Dados da pesquisa

Sobre a competência em ênfase dentre os resultados, Zampier, Takahashi e Teixeira (2011) observam a participação ativa e o comprometimento do gênero feminino em atividades de uma IES, incluindo cargos com forte apego ao gênero masculino. Apuram ainda a crescente preocupação com a realização pessoal e incremento à carreira, a categorizar o retorno financeiro em segundo plano.

Já Lomazini, Vicente e Santos (2014), interligam a forte participação da mulher à frente de diferentes empreendimentos, de maneira direta com competências relacionadas a inovação, ao comprometimento e a competências sociais. Observa-se que a Busca por Oportunidade e Iniciativa se apresenta como a competência com menor pontuação, dentre a amostra apenas 28 mulheres a alcançaram.

Ao analisar a característica empreendedora citada por essas mulheres, nota-se a forte preocupação com a inovação e ao seu perfil de liderança, sendo que para Lenzi et al (2012), a competência é o resultado do conhecimento do indivíduo aliado a sua cultura, experiências e com as estratégias adotadas pela empresa.

A Tabela 04 apresenta uma relação da renda mensal do público da amostra e das mulheres que alcançaram cada competência.

Quanto a análise da renda mensal, a Tabela 04 demonstra que a participação de todas as mulheres da amostra para a análise da renda e o número de mulheres, que alcançaram determinada competência e autodeclaram possuir a renda. Como abordado no diagnóstico do perfil, foi possível identificar a renda entre $\mathrm{R} \$ 938,00$ e $\mathrm{R} \$ 1874,00$ com maior relevância para todas as competências, inclinado para a competências Comprometimento (COM) e para a competência Persistência (PER).

Os resultados apresentam uma tendência maior para o desenvolvimento de competência no público com renda em faixa abaixo de $\mathrm{R} \$ 2000,00$. Pode-se relacionar uma disposição maior ao desenvolvimento de competências em um perfil que busca melhorar sua condição financeira, isso através da criação do próprio negócio ou no desenvolvimento pessoal dentro de uma organização privada. 
Tabela 04: Renda Mensal em relação a cada competência (\%)

\begin{tabular}{|c|c|c|c|c|c|c|c|c|c|c|c|}
\hline Renda & Amostra & BOI & CRC & EQE & PER & COM & BDI & $\begin{array}{l}\text { ED } \\
\text { M }\end{array}$ & PMS & PRC & IAC \\
\hline $\begin{array}{l}\text { Até R\$ } \\
937,00\end{array}$ & 14 & 2 & 6 & 4 & 11 & 11 & 6 & 4 & 7 & 4 & 6 \\
\hline $\begin{array}{l}\text { De R\$ } \\
938,00 \\
\text { a R\$ } \\
1874,00 \\
\end{array}$ & 35 & 9 & 23 & 19 & 28 & 32 & 25 & 14 & 25 & 14 & 14 \\
\hline $\begin{array}{l}\text { De R\$ } \\
1875 \text { a } \\
\text { R\$ } \\
3748,00 \\
\end{array}$ & 20 & 9 & 10 & 10 & 19 & 18 & 14 & 12 & 11 & 8 & 13 \\
\hline $\begin{array}{l}\text { De R\$ } \\
3749 \text { a } \\
\text { R\$ } \\
5622,00\end{array}$ & 19 & 4 & 11 & 12 & 15 & 19 & 17 & 3 & 10 & 7 & 6 \\
\hline $\begin{array}{l}\text { De R\$ } \\
5622,00 \\
\text { a R\$ } \\
7496,00 \\
\end{array}$ & 7 & 3 & 5 & 6 & 6 & 7 & 7 & 6 & 4 & 6 & 5 \\
\hline $\begin{array}{l}\text { De R\$ } \\
7496,00 \\
\text { a R\$ } \\
9370,00 \\
\end{array}$ & 1 & 0 & 0 & 1 & 1 & 1 & 1 & 1 & 0 & 1 & 1 \\
\hline $\begin{array}{l}\text { Mais de } \\
\text { R4 } \\
9371,00\end{array}$ & 1 & 0 & 1 & 1 & 1 & 1 & 0 & 1 & 1 & 1 & 0 \\
\hline
\end{tabular}

Fonte: Dados da pesquisa

Em seguida tem-se disposição para a renda que compreende a faixa entre $\mathrm{R} \$ 1875,00$ e 5622,00, é possível relacionar a mulheres que estão em uma carreira consolidada ou em crescimento, independentemente dos ramos. Ainda dentre a amostra, apenas duas pessoas apresentam renda superior a $\mathrm{R} \$ 7000,00$ e $\mathrm{R} \$ 9000,00$, destaca-se entre essas as competências EQE, PER, COM, EDM e PRC.

À respeito do grau de escolaridade, a pesquisa demonstra a grande quantidade de mulheres com qualificação de $3^{\circ} \mathrm{Grau} / \mathrm{Graduação,} \mathrm{de} \mathrm{modo} \mathrm{a} \mathrm{indicar} \mathrm{uma} \mathrm{tendência} \mathrm{em} \mathrm{que}$ houve intenção por parte desse público de buscar um conhecimento através de um ensino superior para agregar informações e valores ao seu negócio, em que por conseguinte proporciona o aumento da renda dessas mulheres.

A Tabela 05 faz relação com a parte da amostra que apresentou a maior competência da pesquisa, relacionando o ramo de atuação das participantes.

Tabela 05: Ramo de atuação das mulheres com competência COM.

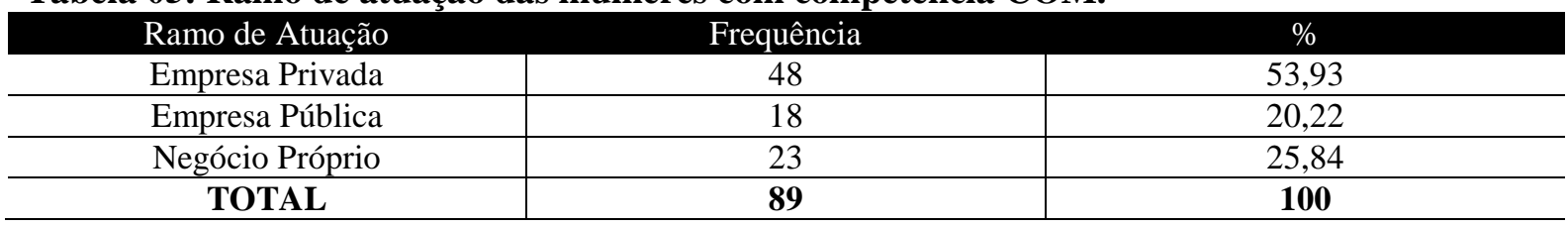

Fonte: Dados da Pesquisa 
Quanto ao ramo de atuação das participantes da pesquisa que apresentam a competência COM, percebe-se a forte participação de mulheres que atuam em organizações privadas e negócios próprios, com ênfase no comércio e educação, colocando em evidência a cooperação do comprometimento e persistência como características importantes para o perfil empreendedor. Cramer et al (2012), expõem a capacidade de o gênero feminino desenvolver várias competências durante os anos, como a facilidade em relacionar-se e em sugerir alternativas criativas.

Questionadas quanto a seu perfil empreendedor, 86,60\% das participantes declaram possuir alguma característica empreendedora, como o Quadro 01 apresenta.

Quadro 01: Mulheres que se consideram com alguma característica empreendedora.

\begin{tabular}{|c|} 
Criatividade, gosto de inovar. \\
\hline Sempre procuro ter qualidade e agilidade. \\
\hline Gosto de liderar e tomar atitudes que possam trazer o bem estar de todos. \\
\hline Perfil de liderança; busco sempre atender as expectativas dos meus clientes. \\
\hline Proatividade! Tem que fazer, só planejar não leva a lugar nenhum. \\
\hline Porque nasci e cresci nesse meio. \\
\hline Disposta a fazer diferente tenho em mente ter uma empresa e estou com planos para mesma. \\
\hline confiança e perseverança. \\
\hline Persuasãon tenho espírito empreendedor, capacidade de planejamento, penso de forma estratégica, além de ter \\
cirme em ideias e propósitos e apresentar objetivos claramente. \\
\hline $\begin{array}{c}\text { Sinto-me preparada após 15 anos de experiência profissional, a ser confiante em um novo projeto gerenciado } \\
\text { por mim. }\end{array}$ \\
\hline $\begin{array}{c}\text { Meu pai e minha mãe tiveram negócio próprio, talvez por ver os dois sempre à frente dos negócios, ativos, } \\
\text { tomando decisões, delegando funções, eu tenha "herdado" esse perfil. Já abri meu próprio negócio também, } \\
\text { que está indo em constante crescimento. }\end{array}$ \\
\hline Considero ter características, pois quero ser uma grande empreendedora de sucesso, e para isso estou \\
estudando e me aperfeiçoando cada vez mais.
\end{tabular}

Fonte: Dados da pesquisa

Verificou-se conforme dados do Quadro 01, que pontos como a capacidade a busca por oportunidades e inovações se fazem presentes na grande maioria das respostas, da mesma forma como a liderança é tema importante em várias respostas. A experiência adquirida durante anos no próprio negócio da família ou em empresa privada para algumas é fator de motivação e encorajamento para seu perfil empreendedor, assim como a persuasão, proatividade, visão, atitude, flexibilidade, facilidade em relacionar-se com pessoas e o comprometimento podem ser citados como fortes pontos para compor o perfil empreendedor.

Dentre os resultados, $13,40 \%$ das mulheres apresentaram não ter alguma característica empreendedora, a relacionar principalmente a falta de coragem ou interesse em ter um negócio próprio, medo de correr riscos, ser cautelosa, ser acomodada e mesmo atuando nos negócios da família não pensa em uma sucessão.

\section{CONSIDERAÇÕES FINAIS}

O presente artigo científico buscou identificar as competências empreendedoras presentes no público feminino, as competências atuais dessas empreendedoras e quais são necessárias para o desenvolvimento pessoal e profissional dentro da organização. Os 
principais resultados indicam o perfil das mulheres com idade entre os 19 e 36 anos, casadas, sem filhos e com renda entre $\mathrm{R} \$ 938,00$ e $\mathrm{R} \$ 3748,00$. Mais da metade das participantes possuem escolaridade em nível de $3^{\circ} \mathrm{Grau} /$ Graduação e afirmam que seus pais não têm negócio próprio. Os ramos de atuação em destaque são o comércio, a educação e o agronegócio. Teve-se maior participação de mulheres do Oeste de Santa Catarina e quanto ao perfil empreendedor, $86,60 \%$ autodeclaram possuírem alguma característica empreendedora.

A capacidade de buscar e identificar oportunidades no mercado, bem como o perfil de liderança e a experiência de ter contato com o próprio negócio da família são os pontos em maior evidência quando questionadas quanto as suas características empreendedoras. Do lado oposto 13,40\% afirmam não possuir características empreendedoras, relacionando isso a falta de coragem, medo de correr riscos ou falta de interesse em possuir o próprio empreendimento.

Ao observar o objetivo do trabalho, a busca pelas competências empreendedoras de Lenzi (2008) resultou em uma ênfase nas competências Comprometimento (COM), seguida de Persistência (PER), e Busca de Informações (BDI), características que trazem destaque para o desenvolvimento pessoal, profissional e competitivo da mulher e da organização que atua. Do lado oposto tem-se as competências com menor representatividade, sendo a Busca de Oportunidade e Iniciativa (BOI) com menor destaque, seguida de Estabelecimento de Metas (EDM) e Persuasão e Rede de Contatos (PRC). Embora nem todas as mulheres exibirem as competências, a média de pontuação se manteve superior a treze para nove competências.

Os resultados da pesquisa indicam uma realidade que o mercado já percebe há algum tempo, mulheres a quebrar os paradigmas tradicionais e aspirando a solidificação de sua carreira, bem como seu incremento pessoal e profissional. A competitividade do gênero é perceptível no nível em que as competências de Comprometimento, Persistência e Busca por informações largam a frente das demais. Da mesma forma, pode-se perceber o quanto a mulher ainda tem a conquistar no mercado de trabalho e dentro do seu próprio perfil, sendo a Busca de Oportunidade e Iniciativa a competência com menor pontuação.

Vale destacar que, tão importante quanto os resultados obtidos, que as limitações da pesquisa venham a contribuir para o desenvolvimento de futuros trabalhos científicos na área. Em meio às limitações, a composição da amostra não permite uma generalização dos dados para o perfil das mulheres, visto que a maior parte das participantes são do oeste do estado de Santa Catarina, e apenas 15,46\% são de outros estados do país.

Por fim, de maneira a considerar todo o conteúdo analisado e confrontado com a teoria abordada, os resultados contribuem para a construção do conhecimento acadêmico sobre um tema emergente. Da mesma forma, o presente estudo poderá contribuir para a construção de futuras pesquisas na área, de modo a levar a maior difusão do tema no cenário atual das instituições de ensino e futuramente no desempenho de seus profissionais no mercado de trabalho.

\section{REFERÊNCIAS}

CARLAND, J. W.; HOY, F.; BOULTON, W. R. et al. Differentiating entrepreneurs from small business owners: A conceptualization. Academy of Management Review, v. 9, p. 354359, 1984.

CRAMER, L.; CAPPELLE, M. C. A.; ANDRADE, L. S.; BRITO, M. J. Representações femininas da ação empreendedora: uma análise da trajetória das mulheres no mundo dos 
negócios. Revista de Empreendedorismo e Gestão de Pequenas Empresas, v. 1, n. 1, p. 0$0,2012$.

FEUERSCHÜTTE, S. G.; GODOI, C. K. Competências de Empreendedores Hoteleiros: um estudo a partir da metodologia da história oral. Turismo: Visão e Ação, v. 10, n. 1, art. 3, p. 39-55, 2008.

FILARDI, F.; BARROS, F. D.; FISCHMANN, A. A. Do homo empreendedor ao empreendedor contemporâneo: evolução das características empreendedoras de 1848 a 2014.

Revista Ibero-Americana de Estratégia, v. 13, n. 3, p. 123-140, 2014.

FILION, L. J., Empreendedorismo: empreendedores e proprietários-gerentes de pequenos negócios. Revista de Administração Contemporânea. São Paulo: v. 34, n. 2, p. 05-28, Abr./Jun. 1999.

FONTENELE, R. E. S.; BRASIL, M. V. O.; SOUSA, A. M. R. Influência da Intenção Empreendedora de Discentes em um Instituto de Ensino Superior. Revista de

Empreendedorismo e Gestão de Pequenas Empresas, v. 4, n. 3, p. 147-176, 2015. FREITAS, H.; OLIVEIRA, M.; SACOOL, A.Z.; MOSCAROLA, J. O método de pesquisa Survey. Revista de Administração, São Paulo, v.35, n. 3, p. 105-112, julho/ setembro. 2000. GIL, Antônio Carlos. Como elaborar projetos de pesquisa. $4^{\circ}$ Edição, São Paulo: Atlas S.A., 2002.

HONMA, E. T.; TEIXEIRA, R. M. Competências empreendedoras em hotéis de pequeno porte: estudo de múltiplos casos em Curitiba, Paraná. Turismo: Visão e Ação, v. 13, n. 1, art. 4, p. 52-80, 2011.

JONATHAN, E.G. Mulheres Empreendedoras: Medos, Conquistas e Qualidade de Vida. Psicologia em Estudo. Maringá, v. 10, n. 3, p. 373-382, set./dez. 2005.

LENZI, F. C.; RAMOS, F.; MACCARI, E. A.; MARTENS, C. D. P. O desenvolvimento de competências empreendedoras na administração pública: um estudo com empreendedores corporativos na Prefeitura de Blumenau, Santa Catarina. Gestão \& Regionalidade, v. 28, n. 82, p. 117-130, 2012.

LENZI, F. C.; SANTOS, S. A. D.; CASADO, T.; KUNIYOSHI, M. S. Empreendedores Corporativos: Um Estudo sobre a Associação entre Tipos Psicológicos e Competências Empreendedoras em Empresas de Grande Porte de Santa Catarina - Brasil. Revista de Administração da Unimep, v. 13, n. 2, p. 117-141, 2015.

LENZI, F. C.. Os empreendedores corporativos nas empresas de grande porte: um estudo da associação entre tipos psicológicos e competências empreendedoras. Tese de doutorado da Universidade de São Paulo, 2008.

LIZOTE, S. A.; VERDINELLI, M. A. Competências empreendedoras: um estudo com funcionários administrativos de uma empresa do ramo alimentício. Revista Pensamento Contemporâneo em Administração, v. 8, n. 1, p. 164-182, 2014.

LIZOTE, S. A.; VERDINELLI, M. A. Relação entre competências empreendedoras e desempenho: um estudo em meios de hospedagem do ambiente rural. Desenvolvimento em Questão, v. 13, n. 29, p. 90-124, 2015.

LOMAZINI, A.; VICENTE, R. C. C.; SANTOS, S. A. F. Tecnologia para produzir chuva: Competências de uma Mulher Empreendedora Social. Revista de Tecnologia Aplicada, v. 3, n. 3, p. 27-41, 2014. 
MACHADO. H.P.V; GAZOLA, S. ANEZ, M.E.M. Criação de empresas por mulheres: um estudo com empreendedoras em Natal, Rio Grande do Norte. RAM, Rev. Adm.

Mackenzie [online]. 2013, vol.14, n.5, pp.177-200, 2013.

MELLO, S. C. B.; LEÃO, A. L. M. S.; PAIVA JÚNIOR, F. G. Competências empreendedoras de dirigentes de empresas brasileiras de médio e grande porte que atuam em serviços da nova economia. Revista de Administração Contemporânea, v. 10, n. 4, p. 4769, 2006.

MENEZES, B. F. R.; COSTA, A. S. M. Experiência de Trabalho e Formação Empreendedora: um Estudo sobre a Empresa Junior PUC- Rio . Revista ADM.MADE, v. 20, n. 1, p. 79-105, 2016.

NASSIF, V. M. J.; ANDREASSI, T.; SIMÕES, F. Competências Empreendedoras: Há Diferenças Entre Empreendedores e Intraempreendedores?. Revista de Administração e Inovação, v. 8, n. 3, art. 28, p. 33-54, 2011.

OLIVEIRA, M. F. Metodologia Cientifica: um manual para a realização de pesquisas em administração. Catalão: UFG, 2011.

ORSI, A.; BOSE, M. Gestão por competência: Modelos e abrangência. Revista de Psicologia, v. 21, n.1/2, 2003.

PAGNONCELLI, V.; ZAMPIER, M. A.; STEFANO, S. R. Competências empreendedoras de proprietários franqueados de escolas de idiomas do interior do Paraná. Revista de

Empreendedorismo e Gestão de Pequenas Empresas, v. 3, n. 3, p. 129-160, 2014. PARDINI, D. J.; BRANDÃO, M. M.; SOUKI, G. Q. Competências empreendedoras e sistema de relações sociais: a dinâmica dos construtos na decisão de empreender nos serviços de fisioterapia. Revista de Negócios, v. 13, n. 1, p. 28-44, 2008.

REIS, E.; MELO, P.; ANDRADE, R.; CALAPEZ, T. Estatística Aplicada 1. $6^{\text {a }}$ Ed, Lisboa: Edições Sílado, 2015.

SILVA, W. A. C.; FONSECA, R. A.; ARAÚJO, E. A. T. Comportamento Empreendedor e Trajetória Empresarial de Fundadores de MPEs em Barão de Cocais/MG. Revista de Empreendedorismo e Gestão de Pequenas Empresas, v. 4, n. 2, p. 33-65, 2015.

SCHUMPETER, J. A. Teoria do desenvolvimento econômico. São Paulo: Abril Cultura, 1989.

SNELL, R.; LAU, A. Exploring local competences salient for expanding small business.

Journal of Management Development, v. 13, n. 4, 1994.

SOUSA, V. D.; DRIESSNACK, M.; MENDES, I. A. C. Revisão dos Desenhos de Pesquisa relevantes para Enfermagem. Parte 1: Desenhos de Pesquisa Quantitativa. Rev Latino-am

Enfermagem, maio-junho, 2007.

ZAMPIER, M. A.; TAKAHASHI, A. R. W. Competências empreendedoras e processos de aprendizagem empreendedora: modelo conceitual de pesquisa. Cadernos EBAPE.BR, v. 9, n. Ed. Especial, art. 6, p. 564-585, 2011.

ZAMPIER, M. A.; TAKAHASHI, A. R. W.; TEIXEIRA, R. M. Intraempreendedorismo feminino e desenvolvimento de competências empreendedoras: um estudo de caso com professoras de Programas de Mestrado e Doutorado em Administração de Curitiba-PR.

Revista Economia \& Gestão, v. 11, n. 25, p. 34-61, 2011. 